\title{
Implementasi Konsep SIDa dalam Upaya Revitalisasi Kawasan Pariwisata Kebon Sirih, Jakarta
}

\section{Implementation of SIDa Concept in Revitalization Efforts of Kebon Sirih Tourism Area, Jakarta}

\author{
TUSY AGUSTIN ADIBROTO \\ Pusat Teknologi Lingkungan, Badan Pengkajian dan Penerapan Teknologi \\ wahyu.purwanta@bppt.go.id
}

\begin{abstract}
Jakarta urban management challenge is increasingly complex due to high population, changing of socioeconomic condition, carrying capacity limitation and need to take notice to new paradigm related to mainstreaming of S\&T and innovation through Co-regulation of Ministry of Research and Technology and Internal Affairs on Strengthening Regional Innovation System (SIDa). SIDa concept development in Jakarta follows factual condition of R\&D institutions absence within Provincial Government Structure due to assumption that various components of SIDa such as best human resources, universities and research activities are already in Jakarta. So, Regional Research Council of Jakarta decided that SIDa strengthening will focus on 2 main issues: a) Interaction which led to collaboration among stakeholders (Academician - Business - Government and Public Society), and b) Learning. The aims is to implement results of studies in selected area of Kebon Sirih that has long been known as homestay location of backpackers which is currently in declining condition. Study conducted using Asset Based Community Development $(A B C D)$ method that focuses on finding local potential both non-physical and physical. The result is proposed Revitalization of Kebon Sirih Tourism Area by developing 2 main potentials: 1) Culinary Center, 2) People's Cultural Center, supported by 3) Environmental Arrangement. Revitalization expected to be carried out by local communities in cooperation with other stakeholders, namely Lurah as Urban Manager, local businesses as CSR funder, academician as implementer of S\&T and innovation, to create independent and competitive urban community that produces resilient and smart communities and the occurrence collaboration among stakeholders.
\end{abstract}

Keywords: SIDa concept, Jakarta Resilience, Jakarta Smart City, ABCD method

\begin{abstract}
ABSTRAK
Tantangan pengelolaan perkotaan di Provinsi DKI Jakarta kian kompleks disebabkan tingginya jumlah penduduk, kondisi sosial-ekonomi yang terus berubah, keterbatasan daya dukung ekosistem serta perlunya memperhatikan paradigma baru terkait pengarusutamaan iptek dan inovasi melalui Perber Menristek dan Mendagri (no.3/2012 dan no.36/2012) tentang Penguatan Sistem Inovasi Daerah (SIDa). Pengembangan konsep SIDa di DKI mengikuti kondisi faktual yaitu tidak adanya kelembagaan Litbang di Pemprov DKI Jakarta dikarenakan anggapan bahwa berbagai komponen SIDa terbaik seperti sumber daya manusia, perguruan tinggi dan berbagai kegiatan riset sudah ada di DKI Jakarta. Untuk itu Dewan Riset Daerah Provinsi DKI Jakarta memutuskan Penguatan SIDa di Jakarta akan berfokus pada 2 isu utama yaitu a) Interaksi yang berujung kolaborasi antar pemangku kepentingan (Akademisi-Dunia UsahaPemerintah Daerah dan Masyarakat Umum), serta b) Pembelajaran. Bertujuan mengimplementasikan hasil kajian pada kawasan terpilih yaitu kelurahan Kebon Sirih yang telah lama dikenal sebagai lokasi homestay turis backpackers dari mancanegara yang saat ini menurun kondisinya. Kajian dilakukan menggunakan metoda Asset Based Community Development (ABCD) yang berfokus mencari potensi baik non-fisik (SDM) maupun fisik. Hasilnya adalah usulan Revitalisasi Kawasan Wisata Kebon Sirih dengan mengembangkan 2 potensi utama: 1) Pengembangan Pusat Kuliner, 2) Pengembangan Pagelaran Budaya Rakyat, yang didukung 3) Penataan Lingkungan. Revitalisasi akan dilaksanakan masyarakat lokal bekerjasama dengan stakeholder lainnya yaitu Lurah selaku Urban Manager, dunia usaha selaku penyandang dana, akademisi dalam rangka penerapan hasil iptek, agar tercipta masyarakat perkotaan yang mandiri dan berdaya-saing yang menghasilkan masyarakat berketahanan dan smart karena menggunakan hasil iptek serta terjadinya kolaborasi antar stakeholder terkait.
\end{abstract}

Kata kunci: konsep SIDa, Jakarta Berketahanan, Jakarta Smart City, metoda ABCD 


\section{PENDAHULUAN \\ 1.1 Latar Belakang}

Saat ini, tantangan dalam penyelenggaraan pengelolaan perkotaan metropolitan di dunia khususnya di negara-negara berkembang termasuk di wilayah DKI Jakarta kian kompleks. Hal tersebut antara lain disebabkan tingginya pertumbuhan jumlah penduduk perkotaan yang telah mencapai 10.177.924 jiwa ${ }^{(1)}$, peningkatan migrasi penduduk ke wilayah perkotaan, peningkatan kegiatan perdagangan dan kegiatan perkotaan lainnya yang berdampak pada antara lain padatnya kondisi transportasi, yang diperparah dengan minimnya kesadaran akan keterbatasan daya dukung ekosistem dan lainnya.Apalagi selain menghadapi kompleksnya dinamika sosial-ekonomi, Jakarta juga harus menghadapi tantangan akibat perubahan iklim. Sebagai salah satu kota terpadat di dunia yang berada di kawasan pesisir dan menjadi muara dari 13 buah sungai, Jakarta juga menjadi rentan terhadap perubahan iklim. Dengan demikian, pembangunan Kota Jakarta hendaknya memperhatikan kondisi sosioekonomik sekaligus dengan aspek lingkungannya.

Atas latar belakang kondisi diatas dan sesuai dengan perkembangan di negara lain yang berhasil mencapai tujuan pembangunannya dengan menerapkan pembangunan berbasis pengetahuan yang telah terbukti dapat mempercepat pembangunannya antara lain Jepang, Korea Selatan, China dan Malaysia dimana inovasi merupakan salah satu isu utama, maka kajian ini dilakukan. Oleh karena itu dirasakan perlu adanya paradigma baru dalam pengelolaan perkotaan, khususnya yang terkait dengan pengarusutamaan aspek ilmu pengetahuan, teknologi dan inovasi yang dapat disingkat sebagai iptekin. Hal tersebut berarti birokrasi Pemerintahan Provinsi DKI Jakarta memerlukan pendekatan baru dalam merencanakan, melaksanakan, dan mengevaluasi program.

Mengusung konsep Sistem Inovasi Daerah (SIDa) khususnya disesuaikan dengan kondisi

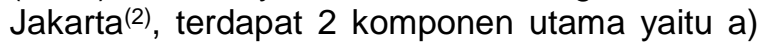
interaksi dan kolaborasi, serta b) pembelajaran, kajian ini melakukan upaya Operasionalisasi Konsep SIDa pada suatu lokasi terpilih dengan topik Revitalisasi Kegiatan Pariwisata di Kawasan Kebon Sirih. Sesuai topiknya, lokasi yang terpilih adalah di Kelurahan Kebon Sirih, wilayah Jakarta Pusat.

Kelurahan Kebon Sirih terpilih menjadi kawasan kajian karena beberapa alasan, antara lain di daerah ini bisa ditemui masalah yang aktual saat ini: hilangnya kampung kota di Jakarta. Kelurahan Kebon Sirih dapat dikatakan menjadi 'korban' dari upaya ekspansi modal yang melihat strategisnya lokasi di kawasan premium Jakarta yaitu di sekitar Monas dengan melakukan alih fungsi lahan yang tadinya merupakan kawasan hunian kelompok kelas menengah bawah. Padahal kawasan ini sudah dikenal sejak lama menjadi tempat homestay bagi para turis backpackers yang tinggal di rumah-rumah penduduk selama di Jakarta(3). Selain itu, dirasakan bahwa aturan yang ada saat ini kurang berpihak pada kelompok bawah.

\subsection{Tujuan Penelitian}

Mendapatkan Konsep Revitalisasi Kawasan Wisata Kebon Sirih dengan Pendekatan SIDa yang sesuai dengan kondisi, potensi dan kebutuhan dengan sebanyak mungkin melibatkan masyarakat lokal termasuk dunia usaha di kawasan tersebut serta didukung aparat pemerintahan lokal, sehingga tercapai masyarakat yang mandiri dan terwujudnya kolaborasi antar berbagai sektor terkait disamping tumbuhnya pembelajaran kolektif.

\section{BAHAN DAN METODE}

Kajian ini dilakukan di Kelurahan Kebon Sirih, Jakarta Pusat yang saat ini banyak berfungsi sebagai kawasan penyedia fasilitas pendukung kepariwisataan.

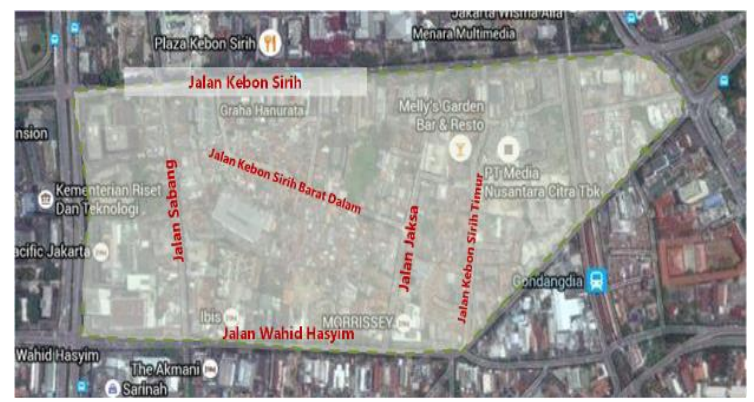

Gambar 1. Lingkup Lokasi Perencanaan

(Sumber: Citra Satelit www.gmap.com)

Diantaranya adalah fasilitas akomodasi (hotel, hostel), fasilitas perbelanjaan, restoran dan rumah makan serta biro perjalanan wisata.

\subsection{Kerangka Pikir}

Tahapan berpikir dalam melaksanakan kajian berupa rumusan input, proses dan output, sebagai berikut.

- Input:latar belakang dilakukannya kajian dan dilanjutkan dengan perumusan hasil survei dan pemetaan kondisi eksisting.

- Proses: tahapan untuk mencapai tujuan/output, dibagi dalam 2 (dua) aspek yaitu a) aspek perbaikan non-fisik, dan b) perbaikan lingkungan fisik. 
- Output; hasil akhir yang diharapkan setelah seluruh rangkaian dicermati dan diimplementasikan.

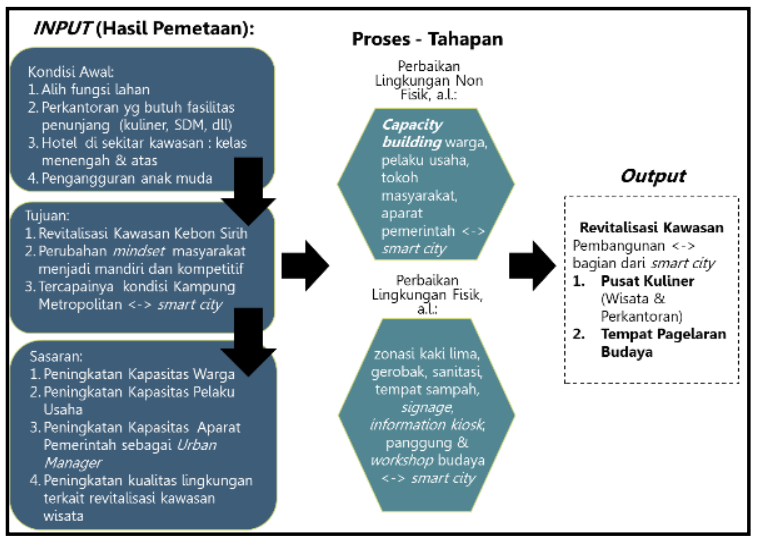

Gambar 2. Alur Pikir Kajian Revitalisasi Kebon Sirih

\subsection{Metodologi dan Analisis}

Metodologi penelitian studi kasus yang dipakai adalah dengan menggunakan teknik pengumpulan data seperti observasi, wawancara, dokumen, survei, roadshow dan sebagainya. Metode ini diperlukan apabila pokok pertanyaan suatu penelitian berkenaan dengan bagaimana dan mengapa, bila penelitian hanya memiliki sedikit peluang untuk mengontrol peristiwa yang akan diselidiki dan bilamana fokus penelitiannya terletak pada fenomena kontemporer di dalam konteks kehidupan nyata(4).

Analisis kajian ini dilakukan dengan menggunakan metoda $\mathrm{ABCD}{ }^{(5)}$ (Asset Based Community Development) yang mengutamakan pemetaan potensi lokal, baik aspek potensi masyarakat maupun potensi fisik. Aset yang tersedia akan dikembangkan menjadi suatu sumberdaya lokal yang dimanfaatkan untuk membangun wilayah dan memecahkan berbagai masalahsehingga pembangunanakan menghasilkan masyarakat setempat yang lebih mandiri.

Masyarakat diharapkan tersadarkan bahwa mereka merupakan bagian terpenting dalam keberlanjutan pembangunan di kawasannya sehingga akan ikut berpartisipasi aktif. ABCD dimulai dengan pemahaman bahwa setiap orang memiliki kapasitas, kemampuan dan bakat ${ }^{(6,7)}$. Komunitas tumbuh secara alami dan dengan metoda $A B C D$ dilakukan identifikasi kapasitas semua anggota pada suatu komunitas dan memastikan bahwa mereka dapat memberikan kontribusi. Yang juga penting, mengidentifikasi orang-orang yang berpotensi menjadi penggerak komunitas (agent of change). Hal ini dilakukan dengan melihat 5 komponen kunci, yaitu melihat a) individu, b) asosiasi, c) institusi yang terbentuk diantara masyarakat, d) aset fisik pada lingkungan, dan e) koneksi atau interaksi yang ada.

Selanjutnya, pendekatan inovasiyang terintegrasi dengan konsep smart city(8) juga menjadi acuan dalam merumuskan hasil kajianyang menitikberatkan pada interaksi-relasi pembelajaran kolektif-komprehensif. Selain itu, juga berkaitan erat dengan konsep City Resilience ${ }^{(9)}$ yang memiliki gagasan utama meningkatkan kapasitas suatu wilayahdengan berfokus kepada urban assets/systems, manmade infrastructure, natural environment, urban management dan human behavior. Ketiganya (Sistem Inovasi-Smart City-City Resilience) pada akhirnya bermuara padatujuan yaitu memperbaiki dan meningkatkan kapasitas dan kapabilitas suatu kota agar dapat menciptakan nilai tambah baru serta memperbaiki kualitas hidup seluruh masyarakat.

\section{HASIL DAN PEMBAHASAN}

\subsection{HASIL}

\section{Kondisi Kependudukan}

\section{1) Jumlah dan Komposisi Penduduk}

Tabel 1. Jumlah Penduduk Kaw. Kebon Sirih

\begin{tabular}{|c|c|c|c|c|c|c|c|c|}
\hline \multirow{2}{*}{ RW } & \multicolumn{3}{|c|}{ WNI } & \multicolumn{3}{|c|}{ WNA } & \multirow{2}{*}{$\mathrm{Jml}$} & \multirow{2}{*}{ KK } \\
\hline & $\mathbf{L}$ & $\mathbf{P}$ & $\mathrm{Jml}$ & $\mathbf{L}$ & $\mathbf{P}$ & Jml & & \\
\hline 01 & 348 & 344 & 692 & - & - & - & 692 & 272 \\
\hline 02 & 935 & 820 & 1.755 & - & - & - & 1.755 & 584 \\
\hline 03 & 912 & 893 & 1.705 & - & - & - & 1.705 & 654 \\
\hline 04 & 853 & 827 & 1.680 & - & - & - & 1.680 & 526 \\
\hline 05 & 563 & 527 & 1.090 & 1 & 1 & 2 & 1.092 & 375 \\
\hline 06 & 557 & 522 & 1.079 & - & - & - & 1.079 & 376 \\
\hline 07 & 385 & 346 & 731 & 1 & 1 & 2 & 733 & 391 \\
\hline Jml & 4.553 & 4.179 & 8.732 & 2 & 2 & 4 & 8.736 & 3.178 \\
\hline
\end{tabular}

\section{2) Kepadatan Penduduk}

Adalah perbandingan antara jumlah penduduk dan luas daerah yang didiami dan tgerkait erat dengan kemampuan wilayah mendukung kehidupan penduduknya. 


\section{3) Jumlah Rukun Tetangga}

Tabel 2. Jumlah Rukun Tetangga Kelurahan Kebon Sirih

\begin{tabular}{ccl}
\hline RW & $\begin{array}{c}\text { Jumlah } \\
\text { RT }\end{array}$ & \multicolumn{1}{c}{ Keterangan } \\
\hline $\mathbf{0 1}$ & 2 & RT.002,003 \\
$\mathbf{0 2}$ & 8 & $\begin{array}{l}\text { RT.003,004,005,006,007,009, } \\
013,014\end{array}$ \\
$\mathbf{0 3}$ & 5 & $\mathrm{RT} .002,003,013,014,015$ \\
$\mathbf{0 4}$ & 6 & $\mathrm{RT} .002,004,005,006,007,008$ \\
$\mathbf{0 5}$ & 6 & $\mathrm{RT} .001,002,003,005,007,009$ \\
$\mathbf{0 6}$ & 3 & $\mathrm{RT} .012,014,016$ \\
$\mathbf{0 7}$ & 6 & $\mathrm{RT} .001,002,004,005,006,008$ \\
\hline Jumlah & \multicolumn{3}{l}{} \\
\hline Sumber: Laporan Kerja Bulanan Kebon Sirih, Juli 2015
\end{tabular}

\section{Kondisi Terkait Aspek Perekonomian}

Tabel 3. Sarana Ekonomi Tahun 2015

\begin{tabular}{lccl}
\hline Jenis Sarana & Jenis Usaha & Jml & \multicolumn{1}{c}{ Ket } \\
\hline Pasar & Umum & 1 & Pasar \\
Warung & Kelontong & 46 & Boplo \\
Swalayan & Umum & 3 & - \\
Mini Market & Umum & 9 & - \\
Usaha & Jokmobil & 39 & - \\
kecil/Bekledin & & & Usaha \\
g & Makanan \& & 94 & turun \\
Pedagang K-5 & Minuman & & temurun \\
& & & yang \\
& & & diberikan \\
& & & izin oleh \\
& & Pemda. \\
\hline Sumber: & &
\end{tabular}

Kebon Sirih memiliki beberapa lokasi wisata kuliner disetiap jalannya baik di toko maupun pedagang kaki lima. Pedagang kaki lima yang telah ada pada umumnya terkesan kurang higienis, antara lain tempatnya yang kurang bersih sehingga perlu diberikan pembinaan agar kondisinya lebih baik, dan lebih bersih.

\section{Kondisi Sosial Budaya}

Berdasarkan hasil wawancara terhadap warga, penduduk yang tinggal di Kebon Sirih terdiri dari : a) warga asli, dan juga b) pendatang. Masyarakat di Kebon Sirih terkesan kurang berpartisipasi aktif dalam peningkatan kualitas hidup di lingkungan. Walaupun demikian, masyarakatnya sangat terbuka, sehingga menarik perhatian khusus untuk turis mancanegara selain lokasinya strategis dan kehadiran penginapan. Hal ini membawa dampak budaya baru di kawasan ini, misalnya turis yang berkumpul di kafe atau bar di jalan Jaksa. Acara yang paling besar setahun sekali yaitu Festival Jalan Jaksa. Untuk mewadahi interaksi warga dan lingkungan, ada beberapa kegiatan antara lain pemilihan Abnon (abangnone) cilik, festival band; stan wisata kuliner dengan sejumlah pameran produk unggulan.

Kebon Sirih juga memiliki beberapa kelompok komunitas, seperti:

1) Karang Taruna: dilaporkan tidak aktif, tapi menurut anggotanya beberapa kegiatan dilakukan seperti kuliner, futsal, meningkatkan minat baca melalui Gerobak Pintar dan Keliling.

2) PKK: Kegiatan rutin adalah pemberantasan jentik nyamuk jumantik (program mingguan) dan posyandu (program bulanan).

3) Majlis Ta'lim: Kegiatan rutinnya adalah pengajian, ibadah bersama, kegiatan sosial dan kegiatan pendidikan.

4) Forum Komunikasi Anak Betawi (FORKABI): Kegiatan yang dilakukan masih kurang terlihat persisnya seperti apa.

\section{Kondisi Geografis dan Konstelasi Lokasi}

Luas wilayah Kawasan KebonSirih adalah $83,40 \mathrm{Ha}$, sedangkan luaslokasi pelaksanaan PSIDa di Kebon Sirih adalah 47.43 ha.

Tabel 4. Luas Wilayah Menurut Status Tanah

\begin{tabular}{cll}
\hline No & Status Tanah & Luas \\
\hline \multirow{2}{*}{1} & Tanah Negara & $12,50 \mathrm{Ha}$. \\
2 & Tanah Milik & $18,25 \mathrm{Ha}$. \\
3 & Tanah Wakaf & $9,75 \mathrm{Ha}$. \\
4 & Tanah Lain- & $6,90 \mathrm{Ha}$. \\
\hline & Lain & $\mathbf{4 7 . 4 3 ~ H a}$ \\
\hline
\end{tabular}

Sumber: Diolah dari hasil wawancara RW

\section{Kondisi Pemanfaatan Lahan}

Tabel 5. Luas Wilayah Menurut Peruntukan Tanah

\begin{tabular}{clc}
\hline No & \multicolumn{1}{c}{ Peruntukan Tanah } & Luas \\
\hline 1 & Perumahan & $34,63 \mathrm{Ha}$. \\
2 & Industri & - \\
3 & Fasilitas Umum & $4,40 \mathrm{Ha}$. \\
4 & Pemakaman & - \\
5 & Lain-Lain & $8,40 \mathrm{Ha}$. \\
\hline \multicolumn{2}{c}{ Jumlah } & $\mathbf{4 7 , 4 3 \mathrm { Ha }}$ \\
\hline \multicolumn{2}{c}{ Sumber: Laporan Kerja Bulanan Kebon Sirih, Maret 2015 }
\end{tabular}

Pendapat warga yang masih bertahan untuk tinggal di wilayah ini. 
Tabel 6. Pendapat Warga Menghadapi Pembelian Lahan Oleh Investor

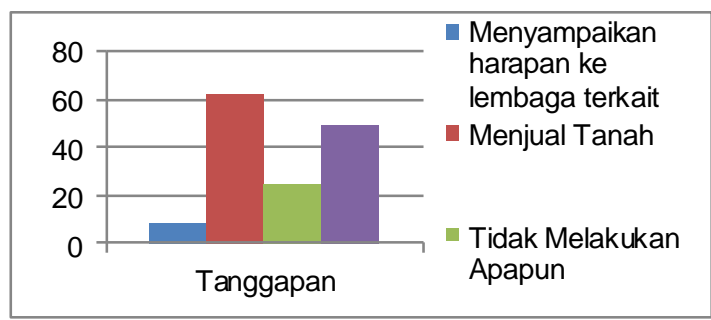

Sumber: Pengolahan Hasil Kuesioner Lapangan, 2015

Wawancara yang dilakukan terhadap tokoh masyarakat setempat yaitu pengurus RW, RT dan Karang Taruna, memperoleh kesan bahwa mereka masih memiliki rasa optimis yang cukup besar untuk warga dapat mengembangkan wilayahnya sendiri.

\section{Kondisi Sirkulasi dan Transportasi}

Kawasan Kebon Sirihdilalui oleh jalan yang padat lalu lintas terutama pada jam masuk dan pulang kantor.

\section{Kondisi Infrastruktur}

Kondisi drainaseberbeda untuk setiap RT. Beberapakondisi drainase cukup baik,lainnya ditemui kondisi drainase yang kotor. Kondisi ini menjadi masalah jika musim hujan datang, akan terjadi genangan air yang hanya berlangsung dalam 1-2 jam saja.

\subsection{PEMBAHASAN}

Analisis Potensi dan Permasalahan PSIDa untuk Struktur Kawasan

\section{1) Pekerjaan dan Penghasilan}

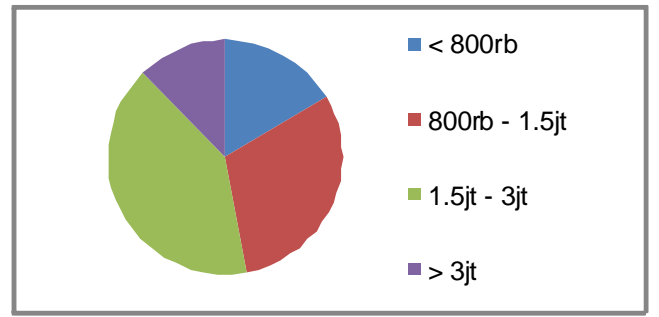

Gambar 3. Grafik Penghasilan Warga

Sumber: Pengolahan Hasil Kuesioner Lapangan, 2015

Bagian terbesar adalah penduduk berpenghasilan 1,5 juta -3 juta dengan jenis pekerjaan sebagai pedagang di toko, karyawan kantor dan office boy.

\section{2) Alasan Tinggal}

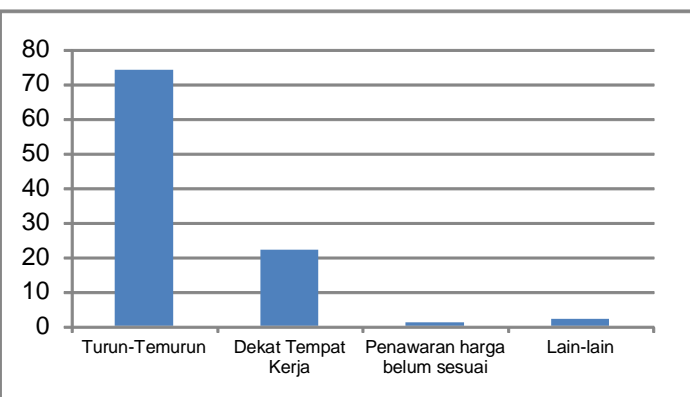

Gambar 4. Grafik Alasan Warga Bertahan Tinggal

Sumber: Pengolahan Hasil Kuesioner Lapangan, 2015

Alasan tinggal didominasi oleh alasan sudah turun temurun serta alasan lain yaitu lokasi strategis karena berada di tengah kota atau dekat dengan fasilitas seperti tempat kerja.

\section{3) Respons warga menghadapi kegiatan di sekelilingnya}

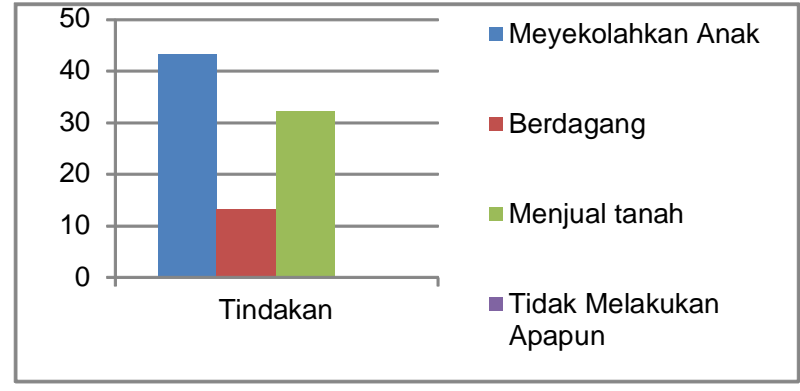

Gambar 5. Grafik Tindakan/Respons warga menghadapi kegiatan sekelilingnya

Sumber: Pengolahan Hasil Kuesioner Lapangan, 2015

Presentase terbesar adalah warga yang memilih menyekolahkan anak agar dapat memenuhi syarat bekerja di perusahaan yang berada di sekitar permukiman.

\section{4) Keluhan Warga}

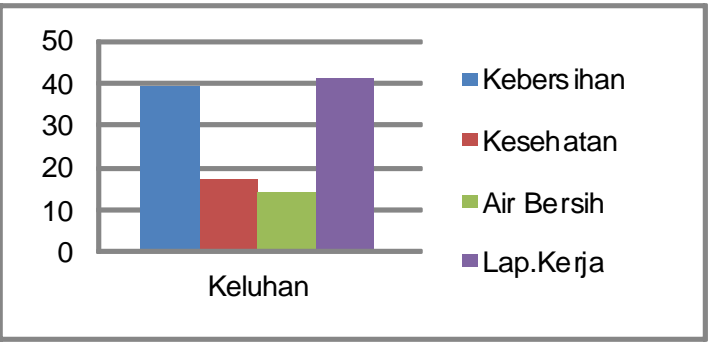

Gambar 6. Grafik Keluhan Warga

Sumber: Pengolahan Hasil Kuesioner Lapangan, 2015

Yang terbesar adalah keluhan tentang sulitnya memperoleh kesempatan kerja, juga tentang aspek kebersihan. 


\section{5) Potensi Warga}

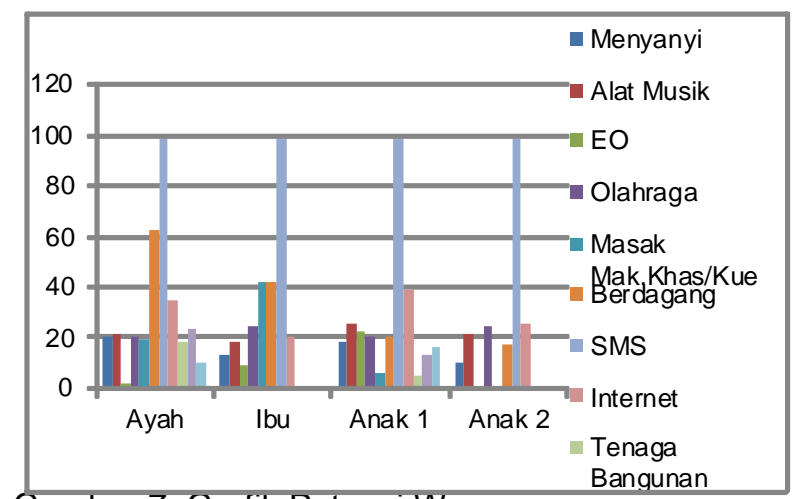

Gambar 7. Grafik Potensi Warga

Sumber: Pengolahan Hasil Kuesioner Lapangan, 2015

Sesuai tabel diatas, potensi ini dapat dikembangkanterkait dengan upaya revitalisasi kawasan wisata yangmengembangkan 'ikon' kawasan sebagai: a) pusat kuliner, dan b) tempat pagelaran rakyat, pada akhirnyadapat menghasilkan nilai tambah baru untuk warga itu sendiri.

Tabel 7. Potensi Warga

\begin{tabular}{cl}
\hline $\begin{array}{c}\text { Anggota } \\
\text { Keluarga }\end{array}$ & \multicolumn{1}{c}{ Potensi } \\
\hline Ayah & $\begin{array}{l}\text { SMS, Dagang, Internet, Mekanik, Main } \\
\text { Musik }\end{array}$ \\
lbu & $\begin{array}{l}\text { SMS, Masak Mak. Khas /Kue, Dagang, } \\
\text { Olahraga, Internet }\end{array}$ \\
Anak 1 & SMS, Internet, Musik, EO, olahraga \\
Anak 2 & SMS, Internet, Olahraga, Musik, Dagang \\
\hline Sumber: Pengolahan Hasil Kuesioner Lapangan, 2015
\end{tabular}

\section{Analisis Aspek Pembelajaran}

Fungsi lembaga-lembaga masyarakat (RT,RW, Kelurahan dan Kecamatan) sebaiknya tidak hanya sebatas menangani urusan administratif masyarakat,tapi dapat lebih dikembangkan menjadi lembaga masyarakat yang juga memiliki tanggung jawab penuh terhadap pengembangan masyarakatnya. Peran Gubernur melalui Peraturan Gubernur diharapkan dapat menjadi alternatif peningkatan fungsi dan peran organisasi masyarakatagar menjadi lebih aktif dan memiliki tanggungjawab lebih besar. Pengalokasian insentif bagi lembaga masyarakat dengan kinerja terbaik juga dapat dilakukan untuk memotivasi kinerja RT, RW, Kelurahan dan Kecamatan. Sebagai instrumen, media sms/internet dapat menjadi salah satu media komunikasi untuk dapat menyebarluaskan informasi penting yang bermanfaat bagi masyarakat.

\section{Analisis Fungsi Ruang}

Untuk menunjang fungsi ruang, ada 2 alternatif yang dapat dikembangkan.

Alternatif Pertama, dibangun kawasan dengan tidak terlalu banyak mengubah kondisi seperti saat ini berupa landed-house. Rumah yang ada ditata kembali dan dilakukan beautifikasi antara lain penghijauan dan dengan menambahkan berbagai ornamen tradisional sehingga tercipta suatu kondisi kampung yang khas dan unik.

Alternatif kedua, dengan melakukan konsolidasi lahan (land consolidation), dimana diharapkan sebagian lahan yang ada dibeli oleh pemerintah daerah dan kemudian dibangun rumah susun untuk warga. Sebagian lahan lainnya dapat dijadikan RTH, yang kemudian dapat dibangun diatasnya tempat pagelaran rakyat, dan pusat kuliner yang tertata rapi serta higienis. Pusat kuliner, selain untuk para wisatawan yang datang juga untuk pasokan perkantoran yang banyak terdapat di sekitar.

Jika meninjau RDTR DKI Jakarta Tahun 2014, Kawasan Kebon Sirih adalah kawasan pemukiman teratur, tepatnya pada RW 02,03,04,05,06, dan 07. Wilayah ini akan dibangun sub zona rumah susun, rumah flat, dan campuran. Pembangunan rumah susun dapat mengurangi penggunaan tanah, membuat ruang-ruang terbuka kota dan digunakan sebagai suatu cara untuk peremajaan kota.

\section{Strategi Revitalisasi Kawasan Pariwisata Kebon Sirih dengan Pendekatan SIDa}

Diawali dengan kegiatan meningkatkan motivasi masyarakat, kemudian dilanjutkan dengan kegiatan meningkatkan kapasitas masyarakat/capacity building serta membentuk adanya komunikasi dan interaksi di antara masyarakat, dunia usaha di sekitarnya maupun aparat pemerintah, pembangunan dapat dilaksanakan bersinergi agar tercapai pembangunan yang berkelanjutan.

Beberapa inisiatif sesuai aspek pembelajaran, yaitu:

\section{1) Peningkatan Motivasi Masyarakat dan Capacity Building Warga}

Upaya meningkatkan motivasi masyarakat dilakukan agar masyarakat sadar akan kemampuan yang dimiliki, potensi diri dan lingkungannya sehingga muncul kepercayaan diri bahwa kawasan Kebon Sirih adalah 'milik' mereka. Untuk selanjutnya, memiliki tanggung jawab untuk mengurus dan memanfaatkannya secara berkelanjutan dan paham bahwa keberadaan mereka di lokasi yang strategis tersebut sesungguhnya memiliki banyak 
peluang yang pada akhirnya dapat meningkatkan kesejahteraan warga.

Kegiatan Capacity Building bagi masyarakat lokal dan stakeholders terkait lainnya (ABG-C), didesain materinya berdasarkan potensi dan kebutuhan. Hal tersebut dilakukan untuk menunjang strategi PSIDa di Kebon Sirih, sebagai keputusan bersama dan pernyataan komitmen bersama bagi implementasi program.

Tabel 8. Aktor Terkait dalam Kegiatan Membangun Motivasi dan Capacity Building Warga

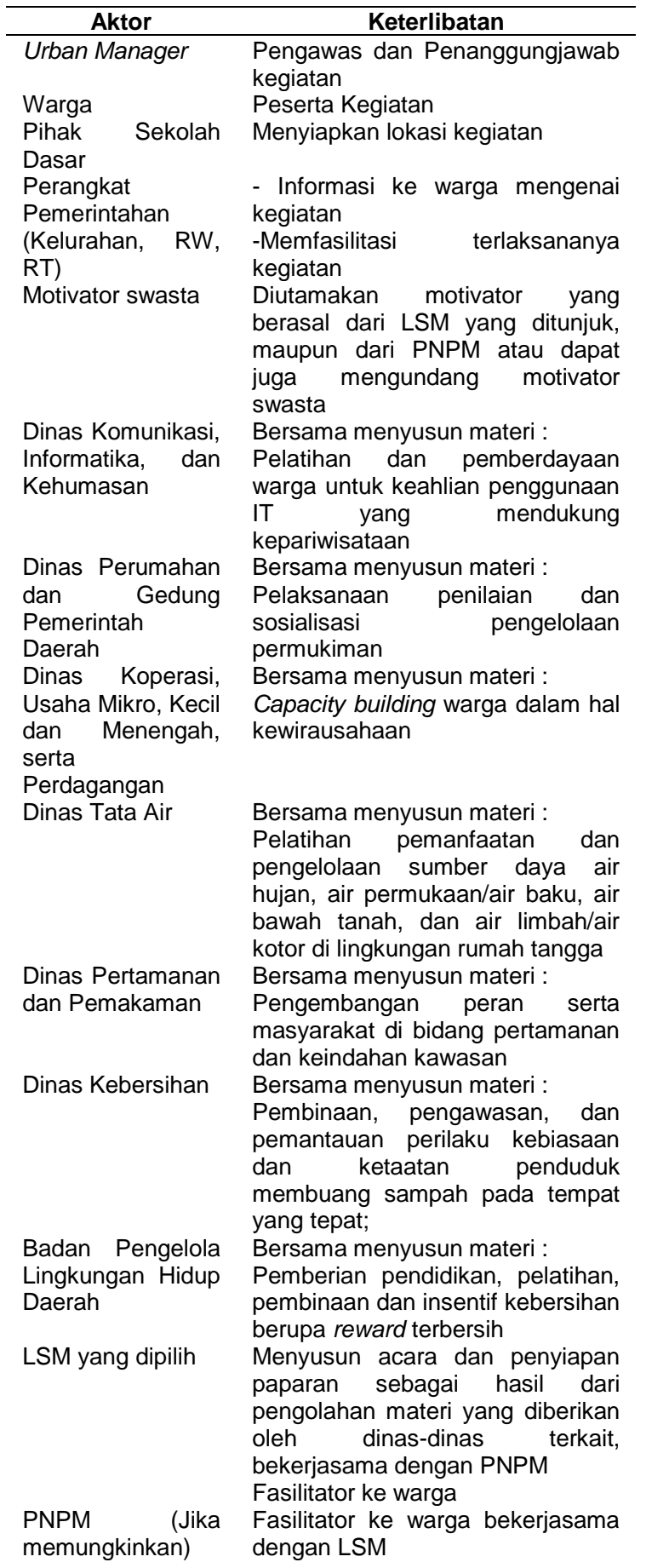

\begin{tabular}{ll}
\hline \multicolumn{1}{c}{ Aktor } & \multicolumn{1}{c}{ Keterlibatan } \\
\hline Pihak Sponsor & $\begin{array}{l}\text { Sosialisasi dan penyebaran } \\
\text { informasi program } \\
\text { Menyediakan fasilitas dan } \\
\text { komitmen dalam rangka tahap } \\
\text { implementasi }\end{array}$ \\
BPMPKB & $\begin{array}{l}\text { Pemberi masukan terhadap materi } \\
\text { pemberdayaan/capacity building, } \\
\text { penasehat dan pengawas kegiatan }\end{array}$ \\
\hline Sumber: Hasil Analisa
\end{tabular}

\section{2) Capacity Building Pelaku Usaha}

Bertujuan memberikan motivasi dan pemahaman dalam rangka peningkatan kapasitas para pelaku usaha terutama pelaku UKM, seperti peningkatan pengetahuan bisnis UKM, penguatan skala usaha, perluasan jaringan, informasi kesempatan, serta pengembangan usaha dengan dukungan teknologi informasi (IT).

Tabel 9. Aktor Terkait dalam Kegiatan Capacity Building Pelaku Usaha

\begin{tabular}{|c|c|}
\hline Aktor & Keterlibatan \\
\hline Urban Manager & $\begin{array}{l}\text { Pengawas dan Penanggungjawab } \\
\text { kegiatan }\end{array}$ \\
\hline $\begin{array}{lr}\text { Dinas } & \text { Koperasi, } \\
\text { Usaha } & \text { Mikro, } \\
\text { Kecil } & \text { dan }\end{array}$ & $\begin{array}{l}\text { - Bersama menyusun materi : } \\
\text { - Pembinaan dan pengembangan } \\
\text { sumber daya manusia pengelola }\end{array}$ \\
\hline $\begin{array}{l}\text { Menengah, serta } \\
\text { Perdagangan }\end{array}$ & $\begin{array}{l}\text { usaha mikro, kecil dan } \\
\text { menengah,serta perdagangan; }\end{array}$ \\
\hline & $\begin{array}{l}\text { - Pemberian pelatihan kepada } \\
\text { pelaku usaha }\end{array}$ \\
\hline & $\begin{array}{l}\text { - Fasilitasi pengembangan } \\
\text { kemitraan antara koperasi, usaha } \\
\text { mikro dan usaha kecil dengan } \\
\text { usaha menengah dan usaha } \\
\text { besar; }\end{array}$ \\
\hline Dinas Tata Air & Bersama menyusun materi : \\
\hline & $\begin{array}{l}\text { Pelatihan pemanfaatan dan } \\
\text { pengelolaan sumber daya air hujan, } \\
\text { air permukaan/air baku, air bawah } \\
\text { tanah, dan air limbah/air kotor di } \\
\text { lingkungan tempat usaha }\end{array}$ \\
\hline $\begin{array}{l}\text { Pelaku Usaha } \\
\text { Kebon Sirih }\end{array}$ & Peserta Kegiatan \\
\hline Sponsor & $\begin{array}{l}\text { Menyediakan fasilitas dan Promosi } \\
\text { Produk }\end{array}$ \\
\hline
\end{tabular}

3) Capacity Building Urban Manager dan Aparat Pemerintah Provinsi DKI Jakarta

Meningkatkan kualitas SDM di kelurahan dan atau kecamatan difokuskan pada peningkatan pengetahuan dan keterampilan termasuk dalam penyiapan database. 
Tabel 10. Aktor Terkait dalam Kegiatan Capacity Building Urban Manager dan Aparat Pemerintah Provinsi DKI Jakarta

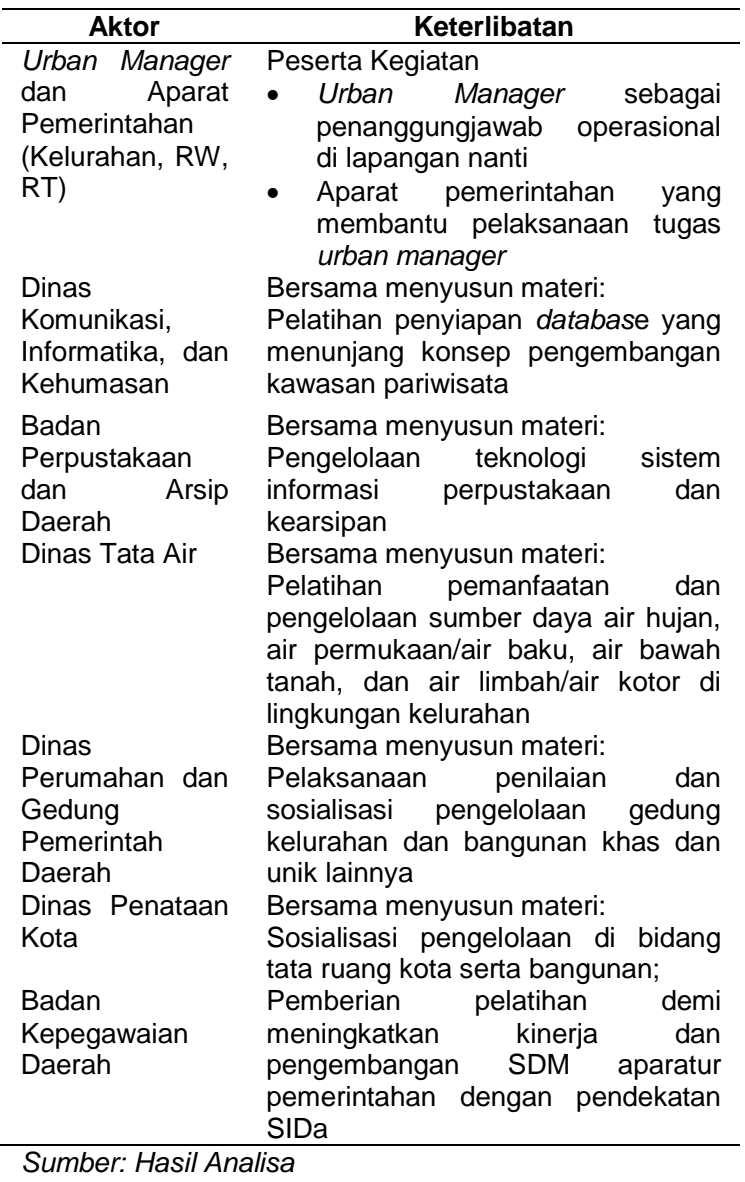

\section{Strategi Pengembangan Kawasan Pariwisata Kebon Sirih dengan Pendekatan SIDa Tahun 2017; Ecopark Kebon Sirih}

Membangun Ecopark ini adalah salah satu bentuk implementasi pembangunan berbasis kawasan dengan pendekatan SIDa yang mengedepankan relasi-interaksi antar aktor terkait serta proses pembelajaran terus menerus ${ }^{(10) .}$ Ecopark dibangun dengan desain multi-use; a) tempat bermain untuk anak, b) tempatpemanfaatan jaringan internet oleh masyarakat, c) RTH/ruang terbuka hijau, d) tempat pengolahan air, e) Gedung Serbaguna yang dipakai sebagai tempat pertemuan masyarakat/komunitas, f)Panggung $P$ gelaran Rakyat yang dikelola masyarakat untuk wisatawan domestik dan mancanegara, dan juga g)tempat Pusat Kuliner baik tradisional maupun modern. Lokasi Ecopark ini memanfaatkan jalur hijaudi bawah jembatan rel kereta api, dimana saat ini sudah berdiri fasilitas RPTRA.

\section{Manajemen Ecopark}

Tabel 11. Aktor Terkait dalam Kegiatan Ecopark

\begin{tabular}{|c|c|}
\hline Aktor & Keterlibatan \\
\hline Urban Manager & $\begin{array}{l}\text { Mengkoordinasikan } \\
\text { stakeholder terkait yang dapat } \\
\text { mendukung terlaksananya Ecopark } \\
\text { Kebon Sirih }\end{array}$ \\
\hline Lurah & Manajemen Kawasan Ecopark \\
\hline Warga & $\begin{array}{l}\text { Aktif melakukan kegiatan di Ecopark } \\
\text { Merawat dan mengawasi Ecopark } \\
\text { Kebon Sirih }\end{array}$ \\
\hline PT KAI & $\begin{array}{l}\text { Menyediakan lokasi lahan untuk } \\
\text { Ecopark yang didalamnya terdapat } \\
\text { kegiatan Pagelaran Kebudayaan } \\
\text { Rakyat }\end{array}$ \\
\hline $\begin{array}{l}\text { Dinas } \\
\text { Pertamanan dan } \\
\text { Pemakaman }\end{array}$ & $\begin{array}{l}\text { Menentukan dan menyediakan jenis } \\
\text { tanaman dan pohon di dalam } \\
\text { Ecopark }\end{array}$ \\
\hline $\begin{array}{l}\text { Dinas } \\
\text { Kebersihan }\end{array}$ & Menjaga kebersihan Ecopark \\
\hline SMK-Kesenian & $\begin{array}{l}\text { Melakukan kegiatan latihan kesenian } \\
\text { dan pertunjukan kesenian di dalam } \\
\text { Zona Pagelaran }\end{array}$ \\
\hline LSM & $\begin{array}{l}\text { Pelaksana Kegiatan dan pendekatan } \\
\text { ke warga dalam Topik Kegiatan } \\
\text { Membangun Mimpi }\end{array}$ \\
\hline $\begin{array}{l}\text { Sponsor/ } \\
\text { Investor }\end{array}$ & $\begin{array}{l}\text { - Dana CSR untuk memfasilitasi } \\
\text { terciptanya EcoparkKebon Sirih } \\
\text { - Promosi produk sponsor di } \\
\text { beberapa titik Ecopark }\end{array}$ \\
\hline
\end{tabular}

\section{Kebijakan yang Diusulkan}

\section{1) Peruntukan Kawasan Kebon Sirih}

$$
\text { Bertujuan menjadikan Kampung }
$$
Metropolitan yang dimasukkan dalam rencana tata ruang.

\section{2) Insentif Pengurangan Biaya PBB}

Untuk warga yang berperan aktif dalam berbagai kegiatan. Serta berbagai jenis usaha perkantoran, perdagangan dan jasa yang aktif melakukan kegiatan Corporate Social Responsibility (CSR) di Kebon Sirih.

\section{3) Peraturan}

Yakni yang terkait dengan pemberhentian tindakan pembelian tanah oleh investor.

\section{KESIMPULAN}

Upaya Revitalisasi Kawasan Kebon Sirih menggunakan konsep SIDa perlu diawali dengan langkah memotivasi masyarakat lokal agar kegiatannya dapat berkelanjutan yang dilanjutkan dengan pelaksanaan peningkatan kapasitas (capacity building), pembagian peran dan fungsi serta tanggung jawab yang saling melengkapi bagi seluruh komponen ABG-C yang didukung dengan Rekomendasi Kebijakan antara lain terkait peruntukan kawasan Kebon 
Sirih, pemberian insentif bagi pihak yang berperan aktif serta dibuatnya peraturan yang dapat menghentikan pembelian tanah oleh investor.

\section{PERSANTUNAN}

Ucapan terima kasih kami ucapkan kepada Pimpinan PTL BPPT serta Pimpinan Dewan Riset Daerah Provinsi DKI Jakarta yang telah memberikan kesempatan untuk melaksanakan kajian terkait dengan upaya implementasi Konsep SIDa dalam rangka mendukung pembangunan daerah agar tercipta masyarakat mandiri dan berdaya-saing dalam menghasilkan produk barang dan jasa berdasarkan potensi lokal sekaligus lapangan kerja.

\section{DAFTAR PUSTAKA}

1. Badan Pusat Statistik (BPS). (2015). Jumlah Penduduk dan Laju Pertumbuhan Penduduk Menurut Kabupaten/Kota di Provinsi DKI Jakarta 2010, 2014, dan 2015. https://jakarta.bps.go.id/statictable/2017/01/ 30/136/jumlah-penduduk-dan-lajupertumbuhan-penduduk-menurutkabupaten-kota-di-provinsi-dki-jakarta-20102014-dan-2015.html

2. Adibroto, Tusy A., Annisa W, Dyah A.G. \& Sofi N.A. (2016). Revitalisasi Kawasan Pariwisata Kebon Sirih (Jl. Jaksa dan sekitarnya) dengan Pendekatan Sistem Inovasi Daerah (SIDa). Jakarta: BPPT Press.

3. Dinas Cipta Karya dan Pertanahan. (2011). Panduan Rancang Kota Khusus Koridor Jalan Jaksa.

4. Yin, R.K. (2012). Applications of Case Study Research (3rd Edition). London: Sage Publications.
5. Green G.P., \& A. Haines (2015). Asset Building \& Community Development (4th Edition). London: Sage Publication.

6. Peters, B. (Ed.). (2013). Applying an AssetBased Community-Driven Development approach in Ethiopia, 2003-2011: Final internal evaluation report. Antigonish, Canada: Coady International Institute.

7. Neil, H. (2017). A comparison between the asset-oriented and needs-based community development approaches in terms of systems changes. Practice, 1-20.

8. Supangkat, S.H. (2016). Smart City Initiatives. In European External Action Services (EEAS) Europa, Delegation Archives.

9. Kete, N. (2014). How to Build a Resilient City: The City Resilience Framework. Women in Clean Energy Symposium.

10. Chung, S. (2002). Building a national innovation system through regional innovation systems. Technovation, 22(8), 485-491. 
